\title{
Burnout and Mindfulness-A Study of South African Employees Working in a Business Process Services Environment
}

\author{
Dr. Rajesh Sharma ${ }^{1}$, Charlene Joanne Sandstrom ${ }^{2}$ \\ ${ }^{1}$ Senior Facilitator and Chair Research, Regenesys Business School, 4 Pybus Road, Corner Katherine Street, Sandton, \\ Johannesburg \\ rajeshs@ @regenesys.co.za \\ ${ }^{2}$ Research Scholar, Regenesys Business School, 4 Pybus Road, Sandton, Johannesburg, South Africa \\ csandstrom@cellc.co.za
}

\begin{abstract}
The business process industry, especially call centre has been responsible for the growth in job opportunities; however, working in a call centre is not always a pleasant experience. The call centre environment is often seen as a stressful one and can create burnout for the individuals who work in it. This research paper hence attempts to explore the degree of burnout in a South African Call Centre and to explore the association of mindfulness and burnout by examining a random sample of 115 Call Centre staff based in the South African telecommunications industry. Two research instruments Utrecht Work Engagement Scale (UWES) and the Mindful Attention Awareness Scale (MAAS) were used in the study, along with a demographic questionnaire. Both these tools have been widely published and have been used within a South African context to assess the validity. The research findings suggest that individuals with higher levels of inherent mindfulness result in lower levels of burnout. In addition, the result of the research also varies within the split between call taking versus back office support staff. The findings of the research study can be utilized by the call centre industry to reduce the burnout of its employees.
\end{abstract}

Keywords-Burnout, Mindfulness, Call Centre, Front Office, Back Office.

\section{INTRODUCTION}

"There is a continuing trend for organisations to use Call Centres, also referred to as Contact Centres, as a preferred channel to service their customers. The call centre is generally made up of customer service representatives who field calls from customers and back office staff who provide support and administration services. The call centre industry has been responsible for the growth in job opportunities and shows no signs of slowing down." Visser (2007). However, as mentioned by Visser (2007) working in a call centre is not always a pleasant experience and the call centre environment is often seen as a stressful one and can create burnout for the individuals who work in it.

A doctoral study in South Africa suggests that up to one fifth of contact centre agents become overly stimulated when working in a contact centre environment. "Contact centre workers are exposed to high amounts of sensory bombardment from the office environment - lighted callboards showing queued calls, ringing phones and computer screens. Their DNA and brain circuits have an over-intake of sensory information," Rossier (2014).

Many contact centre agents cannot maintain a tolerance to the environment. This results in high absenteeism, disproportionate sick leave and attrition (Rossier,2014), which are products of burnout(Ismail,2010). Not only does this cost the company in training, recruitment and the cost of operations, this also impacts on the service delivered to customers which can ultimately also affect a company's bottom line.Vis ser(2007).

"The abrasive nature of call centres and how to deal effectively within this environment needs to be key focus. There needs to be a focus on providing agents in a contact centre with tools to be able to deal with the harsh environment of a call centre to assist in preventing stress." Braithwaite(2011), thus reducing the level of burnout prevalent in a call centre environment.Visser (2007).

"Research conducted with individuals who meditate, appears to provide evidence that those who meditate experience higher quantities of wellbeing and maintained levels of happiness in their lives and reduced levels of burnout. The results include amplified job satisfaction levels and improved optimis $\mathrm{m}$ and morale as well more disposition to contribute and engage with colleagues." Puddicombe(2008).

Mindfulness is one of the results of meditation and a study done by Ismail (2010), stated that individuals with higher levels of mindfulness, be it as a result of 
meditation or a predisposition to mindfulness, are less likely to experience burnout."Those practicing meditation on a regular basis also report that by allowing the mind to settle, to experience calm, they are able to tap into a previously unknown reservoir of creativity." Puddicombe(2008).

This research paper aims to explore the degree of burnout of Call Centre Agents working in a business process industry in a South African Call Centre and to explore the as sociation of mindfulness and burnout.

\section{LITERATURE REVIEW}

Ismail (2010) cites three different literary reviews to describe the three dimensions to burnout-overwhelming emotional exhaustion, depersonalization and reduced personal accomplishment also known as personal efficacy. The study by Carrim (2006) suggests working in a call centre is amongst the top three occupations where people are most unhappy. "Studies conducted have shown up to $70 \%$ of call centre employees display at a minimum, one symptom of stress. It was also recorded that $61 \%$ of these individuals did not experience these stressors prior to being employed within a call centre environment." Carrim (2006). Visser (2007) states that the call centre environment is often seen as a stressful one, even receiving the name "electronic sweatshop".

A study by Harry and Coetzee (2011) concluded that the wellness climate was risky when co mpared to the national norm and found a significant correlation between senses of higher levels of wellbeing, increased feelings of coherence and reduced levels of burnout. The problem was further highlighted by Simons and Buitendach (2013) who believes that Call Centre Agents have a sensory overload with rapid changes in technology, products and high workloads. The consequences of this environment could result in burnout, anxiety, performance issues, absenteeis $m$ and stress.

"Over the last few decades, a lot of focus, interest and investigation has been placed on meditation to play a part in clinical contributions and interventions." Keng ,Smoski and Robins( 2011).Literature on different techniques of meditation suggests that, "Transcendental Meditation (TM) is focusing on a mantra and repeating it for 15 to 20 minutes at a time." Self Help Robot (2013). "Mindfulness is a meditation that involves focusing on the present, to be aware of thoughts in the present with no judgment." Wong (2013). "Guided meditation is where the meditator is guided through the experience verbally." Clarke (n.d.). "Yoga meditation is systematically, observing, understanding and accepting, and training the different levels of being, in order to integrate all parts of one's self dwelling in experience and consciousness." Bharati (n.d.). "With the introduction of mindfulness into Western psychology and medicine, there have been differences on how mindfulness is practiced when comparing Western and Buddhist perspectives." Keng, Smoski and Robins (2011). Keng, Smoski and Robins (2011) further describe mindfulness as having been empirically and theoretically connected with the wellbeing of the psyche." Mindfulness at the work place is suggested by Puddicombe (2008) where he cites that Savvy business leaders are starting incorporate more wholesome values and are increasingly considering meditation or mind training as the answer.

"In 2004, Business Week first announced the arrival of meditation specifically for the workplace. Some of the first pioneers of this were Google, Apple and Yahoo, as well as some of the conventional organisations like McKinsey and Deutsche Bank. Since then there have been countless other organisations that have followed suite" Puddicombe(2008). Discussing the benefits of meditation the study by Melville,Chang, Colagiuri, Marshal, and Cheema (2011) suggests that yoga postures and the meditations acutely improves the physiological and psychological indicators of stress.

Is mail (2010) utilised the Oldenburg Inventory (OLBI) as the measurement for burnout and the Mindful Attention Awareness Scale (MAAS) to measure mindfulness and found a moderately significant correlation between mindfulness and reduced levels of burnout.

Based on the review of the literature across a variety of methodologies of study and meditation practice, there is strong evidence to support that mindfulness may have a positive effect on burnout, improved psychological and possibly even physical ailments for contact centre agents.

\section{RESEARCH DESIGN AND METHODOLOGY}

For this study, the data was collected by random sampling method that involved a structured and specifically designed questionnaire. The copies of the questionnaire were electronically sent out via a free survey tool called Survey Monkey to 2170 Contact Centre staff, based in a South African Call Centre in the telecommunications industry in the month of September 2018. The research was conducted across three locations, two of the locations were based in Johannesburg and the third based in Durban. The questionnaires were emailed to all the respondents allowing three days in which to complete the survey. The total number of respondents were $153(7 \%$ response rate) individuals across the different locations. Of the 153 respondents, 115 individuals completed the survey; the individuals who did not complete the survey were removed from the survey results. This resulted in, a sample size of 115 participants, which equates to a total participation of $5 \%$ of the entire group who received the email to participate in the questionnaire survey. 
The questionnaire contained general demographic questions. The contact centre is made up of call takers and back office staff. The questionnaire requested the participants to select which group they belonged to in order to assess the differences between these two population groups and to ascertain if call takers have higher levels of burnout than the back office staff. A question around meditation training is also asked to identify if the participants have in fact received any mindfulness training interventions, which could account for higher than average mindfulness scores.

Two research instruments utilised in the form of a survey were used in this study, along with a demographic questionnaire. These are the Utrecht Work Engagement Scale (UWES) and the Mindful Attention Awareness Scale (MAAS). Both these tools have been widely published and have been used within a South African context to assess validity. The UWES has seventeen different questions that deal with the three elements of Dedication, Vigour and Absorption. The questions are rated using a Likert scale which ranges from 0 , as never and scales up to 6 which is an indication of everyday occurrence. Similarly MAAS is a 15-item self-reported measure where individuals rate themselves on their mindful states. Individuals rate themselves on how present they are during day-to-day activities using a six point Likert scale which ranges from the bottom of the scale (one) being "almost always" to the top of the scale (six) "almost always".

The data collected by the researchers were further organized for analysis using descriptive statistics along with the analysis of UWES and MAAS. "UWES has displayed sound psychometric properties and proven the validity of UW ES. In addition, this has been tested across different countries to as sess its validity cross nationally." Schaufeli and Bakker (2003). Similarly "MAAS has displayed sound psychometric properties and has been translated into many languages for use in empirical research, suggesting there is confidence in MAAS as a valid mindfulness assessment tool. MAAS was developed to be used in the general population and not only for individuals who are meditators.” Ismail (2010).

\section{RESEARCH FINDINGS AND DISCUSSION}

MAAS was utilised to measure the mindfulness and UWES was used to determine the burnout. To measure an individual's level of Mindfulness, the mean is computed from the 15 questions on the scale. The higher the score the more mindful an individual is.

\subsection{The Prevalence Of Burnout And Engagement}

Descriptive statistics were utilised to determine the frequency of burnout in the realised sample group.
Table.1: UWES and UWES Burnout Score

\begin{tabular}{|l|l|l|}
\hline Description & UWES & $\begin{array}{l}\text { UWES } \\
\text { BURNOUT }\end{array}$ \\
\hline Sample Size & 115 & 115 \\
\hline Mean & 3.92 & 4.04 \\
\hline Minimum Score & 0.06 & 0.09 \\
\hline Maximum Score & 6.00 & 6.00 \\
\hline Median & 4.24 & 4.36 \\
\hline Mode & 4.82 & 4.81 \\
\hline
\end{tabular}

\section{UWES Engagement Score}

The maximu $\mathrm{m}$ score that an individual could score on the 17-question UWES questionnaire-measuring engagement was 6 . The minimum score an individual could score was 0 . In this study, the highest an individual scored was 6; the lowest score recorded on the engagement version of the questionnaire was 0.06 . The higher the score, the more engaged an individual is, and the lower the score the less engaged an individual is.

The most common score amongst the sample was a mode of 4.82. The median (middle) of the sample was a score of 4.24 and the average across the entire sample was a mean of 3.92. This means the entire populations Engagement score was 3.92 for the Call Centre staff.

\section{UWES Burnout Score}

The maximum score that an individual could score on the 9-question UWES burnout version of the questionnaire, was 6 , the minimum score an individual could score was 0 . In this study, the highest an individual scored was 6 on the 9-question burnout version of the questionnaire. The lowest score recorded on the burnout version (with the absorption questions removed) of the questionnaire was 0.09. The higher the score, the more engaged and less burnout an individual is, and the lower the score the less engaged and more burnout an individual is.

The most common score amongst the sample was a mode of 4.81. The median (middle) of the sample was a score of 4.36 and the average across the entire sample was a mean of 4.04. This means the entire populations Burnout score was 4.04 for the Call Centre staff.

\subsection{The Prevalence Of Mindfulness}

Descriptive statistics were utilised to determine the frequency of Mindfulness from the realised sample group. The reason this method was utilised was to determine the number of participants that displayed inherent mindful behaviour through a self-assessment questionnaire and to what extent mindfulness is present in the sample group.

Table.2: MAAS Score

\begin{tabular}{|l|l|}
\hline Description & MAAS \\
\hline Sample Size & 115 \\
\hline Mean & 4.52 \\
\hline
\end{tabular}




\begin{tabular}{|l|l|}
\hline Minimum Score & 1.13 \\
\hline Maximum Score & 6.00 \\
\hline Median & 4.48 \\
\hline Mode & 5 \\
\hline
\end{tabular}

The maximum score that an individual could score on the 15-question MAAS questionnaire was 6; the minimum score an individual could score was 1 . In this study, the highest an individual scored was 6 and the lowest score recorded was 1.13. The higher the score, the more mindful an individual is and the lower the score the lower the individuals Mindfulness.
The most common score amongst the sample was a mode of 5. The median (middle) of the sample was a score of 4.48 and the average across the entire sample was a mean of 4.52. This means the entire populations Mindfulness score was 4.52 for the Call Centre staff.

\subsection{Relationship between MAAS and the UWES Engagement and Burnout Score}

Below are the descriptive statistics for MAAS UWES engagement and UWES burnout. The mean for MAAS is 4.52, UWES engagement 3.92 and UWES Burnout 4.04.

Table.3: UWES vs MAAS Score

\begin{tabular}{|l|l|l|l|}
\hline Description & MAAS & UWES Engagement & UWES Burnout \\
\hline Sample Size & 115 & 115 & 115 \\
\hline Mean & 4.52 & 3.92 & 4.04 \\
\hline Minimum Score & 1.13 & 0.06 & 0.09 \\
\hline Maximum Score & 6.00 & 6.00 & 6.00 \\
\hline Median & 4.48 & 4.24 & 4.36 \\
\hline Mode & 5 & 4.82 & 4.81 \\
\hline
\end{tabular}

When looking at the results from the UWES engagement and burnout results versus the MAAS scores, there appears to be a strong correlation between engagement and mindfulness and between burnout and reduced levels of mindfulness.
When breaking down the MAAS into different scoring categories, there is a relationship between lower MAAS scores and higher levels of burnout and higher levels of engagement when comparing against the mean of each score.

Table.4: UWES vs MAAS Score Version 2

\begin{tabular}{|l|l|l|l|l|}
\hline MAAS & UWES Burnout & $\begin{array}{l}\text { UWES } \\
\text { Engagement }\end{array}$ & $\boldsymbol{N}$ & $\boldsymbol{n}$ percentage \\
\hline $5.00-6.00$ & 4.33 & 4.13 & 46 & $40 \%$ \\
\hline $4.00-4.99$ & 4.32 & 4.15 & 38 & $33 \%$ \\
\hline $3.00-3.99$ & 3.42 & 3.44 & 20 & $17 \%$ \\
\hline $2.00-2.99$ & 3.66 & 3.77 & 7 & $6 \%$ \\
\hline $1.00-1.99$ & 1.75 & 1.93 & 4 & $3 \%$ \\
\hline 4.52 (Mean) & 4.04 (Mean) & 3.92 (Mean) & 115 (Total) & $100 \%$ \\
\hline
\end{tabular}

Individuals scoring higher on the MAAS with a score between $5.00-6.00$ and an $n$ of $46(40 \%)$ showed an increase in engagement of 4.13 compared to the mean of 3.92 and burnout levels are lower with a score of 4.33 compared to the overall mean of 4.04 .

When comparing individuals with a MAAS score between $4.00-4.99$ and an $n$ of 38 (33\%), there still shows increased levels of engagement with a score of 4.15 compared to the mean of 3.92 and burnout levels are lower with a score of 4.32 compared to the overall mean of 4.04 .

However when looking at the MAAS score between 3.00 -3.99 and an $n$ of $20(17 \%)$ the levels of engagement and burnout reduces below the samples mean. Engagement sits at 3.42 versus the mean of 4.04 and burnout sits at 3.44 versus the mean of 3.92 .

When analysing the MAAS scores between $2.00-2.99$ and an $n$ of $7(6 \%)$ there is a further reduction on engagement and an increase in burnout compared to the groups mean. Engagement sits at 3.77 versus the mean of 4.04 and burnout sits at 3.66 versus the mean of 3.92 . Slightly higher than the MAAS of 3.00-3.99, however, as the percentage of the sample gets smaller the results could be less reliable.

Individuals who scored $1.00-1.99$ on the MAAS and with an $n$ of $4(3 \%)$ have the lowest engagement and 
highest burnout scores of all the MAAS grouped scores with an engagement score of 1.75 versus the mean of 3.92 and a burnout score of 1.93 versus a mean of 4.04 . The $n$ on this group is low and it would therefore be practical to group the MAAS results into fewer categories for a stable statistical sample.

Table.5: UWES vs MAAS Score Version 3

\begin{tabular}{|l|l|l|l|l|}
\hline MAAS & UWES Burnout & UWES Engagement & $\boldsymbol{N}$ & $\boldsymbol{n}$ percentage \\
\hline $4.00-6.00$ & 4.32 & 4.14 & 84 & $73 \%$ \\
\hline $1.00-3.99$ & 3.26 & 3.31 & 31 & $27 \%$ \\
\hline 4.52 (Mean) & 4.04 (Mean) & 3.92 (Mean) & 115 (Total) & $100 \%$ \\
\hline
\end{tabular}

When categorising MAAS into just two groups those who scored between $4.00-6.00$, with an $n$ of $84(73 \%)$ and individuals who scored $1.00-3.99$, with an $n$ of $31(27 \%)$ the results show the same trends. Individuals who scored higher on the MAAS, $4.00-6.00$ showed higher levels of engagement, 4.14 versus the mean of 3.92 and lower levels of burnout, with a score of 4.32 versus the mean of 4.04 .

Individuals who scored lower on the MAAS, $1.00-3.99$ showed lower levels of engagement, 3.31 versus the mean of 3.92 and higher levels of burnout, with a score of 3.31 versus the mean of 4.04 .

Table.6: UWES vs MAAS Score Version 4

\begin{tabular}{|l|l|l|l|l|}
\hline MAAS & UWES Burnout & UWES Engagement & $\boldsymbol{N}$ & $\boldsymbol{n}$ percentage \\
\hline $3.00-6.00$ & 4.15 & 4.00 & 104 & $90 \%$ \\
\hline $1.00-2.99$ & 2.97 & 3.10 & 11 & $10 \%$ \\
\hline 4.52 (Mean) & 4.04 (Mean) & 3.92 (Mean) & 115 (Total) & $100 \%$ \\
\hline
\end{tabular}

When categorising MAAS into two groups, with a lower MAAS category, those who scored between $3.00-6.00$, with an $n$ of $104(90 \%)$ and individuals who scored $1.00-$ 2.99 , with an $n$ of $11(10 \%)$ the results show the same trends. Individuals who scored higher on the MAAS, $3.00-6.00$ showed higher levels of engagement, 4.00 versus the mean of 3.92 and lower levels of burnout, with a score of 4.15 versus the mean of 4.04 .

Individuals who scored lower on the MAAS, $1.00-2.99$ showed the lowest levels of engagement, 3.10 versus the mean of 3.92 and highest levels of burnout, with a score of 2.97 versus the mean of 4.04 .

\subsection{Front Office Versus Back Office}

The population was split into Back Office / Support Staff and Call Taking Staff. The Back Office / Support Staff made up $29 \%(n=33)$ of the total sample group and the Call Taking Staff made up the balance of $71 \%(n=82)$ of the total sample group.

Table.7: Front Office versus Back Office

\begin{tabular}{|c|c|c|c|c|c|}
\hline & Count & $\%$ & $\begin{array}{l}\text { Average of } \\
\text { MAAS Score }\end{array}$ & $\begin{array}{ll}\text { Average } & \text { of } \\
\text { UWES } & \\
\text { Engagement } & \end{array}$ & $\begin{array}{l}\text { Average of } \\
\text { UWES Burnout }\end{array}$ \\
\hline $\begin{array}{l}\text { Back Office/ Support } \\
\text { Staff }\end{array}$ & 33 & $29 \%$ & 4.65 & 4.53 & 4.62 \\
\hline Call Taking Staff & 82 & $71 \%$ & 4.47 & 3.67 & 3.80 \\
\hline Grand Total & 115 & $100 \%$ & 4.52 & 3.92 & 4.04 \\
\hline
\end{tabular}

The Back Office / Support Staff had a MAAS score of 4.65, higher than the mean of 4.52 of the entire population. In addition, their UWES burnout score was 4.62 significantly higher than the mean of 4.04 and their engagement score was 4.53 significantly higher than the mean of 3.92 of the entire population.

The Call Taking Staff had a MAAS score of 4.47, lower than the mean of 4.52 of the entire population. In addition, their UWES burnout score was 3.80 significantly lower than the mean of 4.04 and their engagement score was 3.67 significantly lower than the mean of 3.92 of the entire population. These scores reveal that the Call Taking Staff have lower levels of mindfulness, higher levels of burnout and lower levels of engagement.

\section{DISCUSSION ON THE FINDINGS OF THE STUDY}


When comparing this study of the Contact Centre in a Telecommunications company to the results of the study by Bruin (2013), the South African participants in the Telecommunications Call Centre appear to be more burnt out and less engaged than the South African participants from the ICT company. The mean of UWES Engagement questionnaire for the ITC Company was 4.50 versus a mean of 3.92 in this study of the Call Centre in a Telecommunications Company. The same trend can be seen in UWES Burnout results where the ICT Company had a mean of 4.51 versus a mean of 4.04 recorded from the Call Centre in the Telecommunications Company.

This provides strong evidence to support the theory that a Contact Centre environment is a more challenging environment to work in and as per the paper written by Visser (2007) where it was stated that the call centre environment is often seen as a stressful one and creates burnout for the individuals who work in it.

When comparing the UWES engagement mean score of 3.92 with the UWES mean burnout score of 4.04, the scores show that the staff are less engaged, the scores indicate that they are less burnt-out versus their lower levels of engagement.

Looking at the prevalence of Mindfulness in the Call Centre, the average across the entire sample was a mean of 4.52. This means the entire populations Mindfulness score was 4.52 for the Call Centre staff. This is higher than the study by Ismail (2010) where the MAAS mean was 4.36, where the sample constituted 207 individuals from a bank based in Johannesburg.

The study on the relationship between MAAS and UWES shows that there is a distinct relationship between lower MAAS scores and higher levels of burnout and higher levels of engagement when comparing against the mean of each score.

Individuals scoring higher on the MAAS with scores between $5.00-6.00,40 \%$ of the entire sample population, showed an increase in engagement of 4.13 compared to the mean of 3.92 and burnout levels are lower with a score of 4.33 compared to the overall mean of 4.04.

When comparing individuals with a MAAS scores between $4.00-4.99,33 \%$ of the entire sample population, there still shows increased levels of engagement with a score of 4.15 compared to the mean of 3.92 and burnout levels are lower with a score of 4.32 compared to the overall mean of 4.04 .

However when looking at the MAAS scores between 3.00 - 3.99, $17 \%$ of the entire population, the levels of engagement and burnout reduces below the sample's mean. Engagement sits at 3.42 versus the mean of 4.04 and burnout sits at 3.44 versus the mean of 3.92 . Indicating that below 3.99 is what may be considered a low MAAS score, within this sample group. Suggesting that a MAAS score lower than 3.99 will begin to have a negative influence on the individual's engagement and burnout scores. Meaning, individuals with a MAAS score lower than 3.99 could potentially begin to exhibit higher levels of burnout and lower levels of engagement.

When analysing the MAAS scores between $2.00-2.99$, a smaller sample of only $6 \%$ of the entire population, there is a further reduction on engagement and an increase in burnout compared to the groups mean. Engagement sits at 3.77 versus the mean of 4.04 and burnout sits at 3.66 versus the mean of 3.92. Slightly higher than the MAAS of 3.00-3.99, however, below the populations mean. A consideration is that as the percentage of the sample gets smaller the results could be less reliable as any anomalies in the individual data could be perceived.

Individuals who scored $1.00-1.99$ on MAAS, a very small sample of $3 \%$ of the total population, have the lowest engagement and highest burnout scores of all the MAAS grouped scores with an engagement score of 1.75 versus the mean of 3.92 and a burnout score of 1.93 versus a mean of 4.04. The $n$ on this group is low and it would therefore be practical to group the MAAS results into fewer categories for a stable statistical sample.

The above statists show a strong correlation between lower levels of inherent mindfulness and higher levels of burnout and lower levels of engagement. Which correlates to the research conducted by Ismail (2010) where he stated that individuals with higher levels of mindfulness, be it as a result of meditation or a predisposition to mindfulness, are less likely to experience burnout. In the research conducted by Ismail (2010) he found a strong correlation of individuals who were mindful and reported lower cases of burnout within a corporate company in South Africa. The research in this report has also identified that higher levels of mindfulness, which has been reported can be achieved through meditation, does appear to benefit Contact Centre Agents in a South African telecommunications Call Centre, despite their environment.

If the individuals with the Contact Centre could take part in a meditation training initiative this could significantly improve their MAAS score, bringing up the population average and positively influencing the UWES engagement scores and reducing the levels of burnout as identified by the UWES burnout score.

When the results of the population were split into Back Office / Support Staff and Call Taking staff levels of burnout levels are far more evident from the Call Taking staff. The results also indicate that the low scores of the Call Taking staff influenced the mean of the scores for all three metrics, MAAS, UWES Engagement and UWES Burnout.

The Back Office / Support Staff made up 29\% of the total sample group and the Call Taking Staff made up the balance of $71 \%$ of the total sample group. The Back 
Office / Support Staff UWES burnout score was 4.62 significantly higher than the mean of 4.04 and their engagement score was 4.53 significantly higher than the mean of 3.92 of the entire population.

The Call Taking Staff had a UW ES burnout score of 3.80, significantly lower than the mean of 4.04 and their engagement score was 3.67 significantly lower than the mean of 3.92 of the entire population. These scores reveal that the Call Taking Staff have significantly higher levels of burnout and significantly lower levels of engage

\section{LIMITATIONS}

This study did have certain limitations that need to be considered when reviewing the data.

The familiarity of the scales (UWES and MAAS) or lack thereof could influence the results. To add-on, the population of this study did not have accurate representation across all the subgroups by demographic information. Therefore, interpretation of some results meant the sample size was minute, which could have created a skew in data and not be statistically sound.

Another limitation was that the study sampled from a single organization and may therefore not be representative of all Call Centres within the South African context and hence the findings of the study cannot be generalized.

\section{CONCLUSIONS AND RECOMMENDATIONS}

The results of this research have established that individuals with higher levels of inherent mindfulness result in lower levels of burnout. In addition, the results of the research have also confirmed that call centres display higher levels of burnout. However the split between call taking versus back office/support staff within this study reveals that the call takers have lower MAAS scores than the mean of the group and lower than the back office staff. In addition, their UWES Engagement and Burnout scores are significantly lower than the back office staff and the mean of the entire sample. This indicates that the dissatisfaction, burnout and stress levels of call takers are significantly higher than the back office staff.

The researchers would like to recommend rotating the staff from call taking to back office support regularly. This would provide individuals who are call takers a reprieve from the harsh environment, meaning the time spent on calls is not for an excessively long duration. A further recommendation with these results indicating a substantial converse correlation between mindfulness and burnout is to introduce a mindfulness -training programme that would benefit the Call Centre to improve the undesirable effects of burnout in the organisation.

\section{REFERENCES}

[1] Barnert, E. et al. (2013). "Innovations in Practice: exploring an intensive meditation intervention for incarcerated youth." Retrieved from

http://www.mbaproject.org/wpcontent/uploads/2012/03/MBA-Project-Child-andAdolescent-Mental-Health-Innovations-in-PracticeBarnert-Himelstein-etc.-2013.pdf (Accessed July 2018].

[2] Bharati, S. J., n.d. "What is Yoga Meditation." Retrieved from http://swamij.com/yoga-meditation.htm (Accessed March 2018).

[3] Brathwaite, D. J. (2011). "Call Centre Stress." Retrieved from http://ezinearticles.com/?Call-Centre-

\section{$\underline{\text { Stress \&id }=6268813}$}

[Accessed November 2018].

[4] Bruin, G. d., Hill, C., Henn, C. and Muller, K.(2013). "Dimensionality of the UWES-17: An item response modelling analysis." Retrieved from http://www.scielo.org.za/scielo.php?pid=S2071$\underline{07632013000200010 \& \text { script }=\text { sci } \text { artte xt }}$

[Accessed November 2018].

[5] Carrim, N. (2006). "The Relationship Amongst Locus Of Control, Self Determination And Job Satisfaction In Call Centres." Retrieved from http://repository.up.ac.za/bitstream/handle/2263/285 46/dissertation.pdf? sequence $=1$

[Accessed November 2018].

[6] Clarke, D. C. L., n.d. "What is Guided Meditation?" Retrieved from http://www.the-guided-meditation-site.com/what-isguided-meditation.html [Accessed March 2014].

[7] Harry, N and Coetzee, M. (2011). "Sense of coherence, affective wellbeing and burnout in a South African higher education institution call centre." Retrieved from http://uir.unisa.ac.za/xmlui/bitstream/handle/10500/ 5549/C9841d01.pdf?sequence $=1$

[Accessed October 2015].

[8] Ismail, H. (2010). "The Relationship Between Mindfulness and Burnout Amongst Employees in a South African Corporate Organisation."Dissertation, University of Johannesburg.

[9] Keng, S. L., Smoski,M.J. and Robins,C.J. (2011). "Effects of Mindfulness on Psychological Health: A Review of Empirical Studies." Retrieved from http://www.ncbi.nlm.nih.gov/pmc/articles/PMC3679 $\underline{190 /}$

[Accessed November 2018]. 
[10] Melville, G.W., Chang, D., Colagiuri, B., Marshal, P.W., and Cheema, B. S.(2011). "Fifteen Minutes Of Chair- Based Yoga Postures Or Guided Meditation Performed In The Office Can Elicit A Relaxation Response." Evidence-Based Complementary and Alternative Medicine, 2012(501986).

[11] Puddicombe, A. (2008). "Meditation in the workplace. "Retrieved from http://www. managementissues.com/opinion/4723/meditation-in-theworkplace/ (Accessed September 2018).

[12] Rossier, Z. (2014). "What's it's really like to work in a call centre." Retrieved from http://www.health24.com/Lifestyle/Healthyworkplace/Work-and-stress/Call-centre-blues$\underline{20120721}$

[Accessed November 2018].

[13] Schaufeli, W. B., Leiter, M. P., and Maslach, C. (2009)."Burnout: 35 years of research and practice." Career Development International, 14(3),204-220.

[14] Self Help Robot, 2013 . "A Transcendental Meditation Mantras List That You Can Use Now." Retrieved from http://selfhelprobot.com/51-transcendentalmeditation-mantras-list [Accessed October 2018].

[15] Simons, J. \& Buitendach, J. (2013). "Psychological Capital, Work Engagement and Organisational Commitment Amongst Call Centre Employees in South Africa." Retrieved from

[16] http://www.scielo.org.za/pdf/sajip/v39n2/18.pdf [Accessed November 2018].

[17] Visser, W. A. (2007). "Daily Hassles, Resilience, and Burnout of Call Centre Staff." Retrieved from

[18] http://dspace.nwu.ac.za/bitstream/handle/10394/170 1 visser willema.pdf?sequence $=1 \quad$ (Accessed October 2018).

[19] Wong, C., 2013. "Mindfulness Meditation." Retrieved from http://altmedic ine.about.com/cs/mindbody/a/Meditat ion.htm [Accessed November 2018]. 